Article

\title{
Ressentiment: A Complex Emotion or an Emotional Mechanism of Psychic Defences?
}

\author{
Mikko Salmela ${ }^{1,2, *}$ and Tereza Capelos ${ }^{3}$ \\ ${ }^{1}$ Faculty of Social Sciences, University of Helsinki, Finland; E-Mail: mikko.salmela@helsinki.fi \\ ${ }^{2}$ Centre for Subjectivity Research, Department of Communication, University of Copenhagen, Denmark \\ ${ }^{3}$ Department of Political Science and International Studies, University of Birmingham, UK; E-Mail: t.capelos@bham.ac.uk \\ * Corresponding author
}

Submitted: 5 March 2021 | Accepted: 13 June 2021 | Published: 27 August 2021

\begin{abstract}
Ressentiment is central for understanding the psychological foundations of reactionary politics, right-wing populism, Islamic fundamentalism, and radicalism. In this article we theorise ressentiment as an emotional mechanism which, reinforcing a morally superior sense of victimhood, expedites two parallel transvaluation processes: What was once desired or valued, yet unattainable, is reassessed as something undesirable and rotten, and one's own self from being inferior, a loser, is reassessed as being noble and superior. We establish negative emotions of envy, shame, and inefficacious anger as the main triggers of ressentiment, with their associated feelings of inferiority and impotence, which target the vulnerable self. We identify the outcomes of ressentiment as other-directed negative emotions of resentment, indignation, and hatred, reinforced and validated by social sharing. We map the psychological structure of ressentiment in four stages, each employing idiosyncratic defences that depend on the ego-strength of the individual to deliver the transvaluation of the self and its values, and finally detail how social sharing consolidates the outcome emotions, values, and identities in ressentiment through shallow twinship bonds with like-minded peers. Our interdisciplinary theoretical account integrates classic philosophical scholarship of ressentiment and its contemporary proponents in philosophy and sociology, which highlight envy as the prime driver of ressentiment; it also considers the sociological approaches that focus on the repression and transmutation of shame and its social consequences, as well as the psychoanalytic scholarship on psychic defences and political psychology models on the emotionality of decision-making. We conclude the article by elaborating the political implications of ressentiment as the emotional mechanism of grievance politics.
\end{abstract}

\section{Keywords}

emotional mechanism; philosophy; political psychology; psychic defences; psychoanalysis; reactionism; resentment; ressentiment; sociology

\section{Issue}

This article is part of the issue "Reactionary Politics and Resentful Affect in Populist Times" edited by Tereza Capelos (University of Birmingham, UK), Stavroula Chrona (King's College London, UK), Mikko Salmela (University of Helsinki, Finland / University of Copenhagen, Denmark), and Cristiano Bee (Oxford Brookes University, UK).

(C) 2021 by the authors; licensee Cogitatio (Lisbon, Portugal). This article is licensed under a Creative Commons Attribution 4.0 International License (CC BY).

\section{Introduction}

Aesop's fable of the fox and the grapes tells of a fox's frustrated and repeated failures to reach the grapes it covets, and ends with the fox's scornful belittling of the sour grapes. The technical term "ressentiment" was introduced by Nietzsche (1885/1961) and elabo- rated by Scheler (1915/1961) to capture this insulating and compensatory psychological phenomenon that is distinguished from resentment. Despite its relevance for understanding backlash and reactionary politics, not much attention has been paid to its psychological profile.

In this article, we theorise ressentiment as an emotional mechanism, identify its psychological properties, 
outline its function for individuals and collectives, and consider its implications for democratic politics. We start from the premise that ressentiment is witnessed among the powerless, disprivileged, and weak-including those who experience their situation as precarious or vulnerable, however well positioned. We identify its main function is to manage frustration through expediting two parallel transvaluation processes: What was desired/valued, yet unattainable, is reassessed as undesirable and rotten; and one's own self from being inferior, a loser, is reassessed as being noble and superior. We explain how ressentiment employs effective (but eventually maladaptive) defences helping individuals resist their insecurities and flaws without acknowledging or resolving them. We also elaborate that the gains from ressentiment are evidenced in internal and external relations. Internally, the mental pain of facing one's perceived inferiority and impotence is evaded, and the ressentimentful individual feels righteous anger, resentment, and hatred. In external relations, the "improved new self" is validated and maintained through social sharing with like-minded peers. The residual frustration, never fully repressed, targets external objects (the establishment, political elites, immigrants, media) perceived as hostile, bad or inferior, and delivers rejection, vilification, and blame.

Ressentiment is identified as the affective driver of reactionism, both on the political right and left (Capelos \& Demertzis, 2018; Capelos \& Katsanidou, 2018; Capelos et al., 2021; Sullivan, 2021). Ressentiment and its bitter outcome emotions-resentment and hatred-are featured in studies of right-wing populism (Betz, 2005; Celis et al., 2021; Ferrari, 2021; Hoggett et al., 2013; Kiss, 2021; Mishra, 2017; Salmela \& von Scheve, 2017), Islamic and other forms of fundamentalism, fanaticism, extremism, and radicalism (Griffin, 2012; Katsafanas, in press; Kaya, 2021; Langman \& Morris, 2003; Mishra, 2017; Posłuszna \& Posłuszny, 2015), and have recently been linked to narcissism and cynicism (Capelos et al., 2021; Demertzis, 2020; Mayer \& Nguyen, 2021).

Scholars of ressentiment agree it begins with negative emotions and feelings targeting the vulnerable self. The transvaluation of the self and its values allows the projection of negative emotions towards generic "all-bad" others. However, there are several open questions about ressentiment, namely: (1) Is it a complex emotion composed of other discrete emotions (Demertzis, 2020; Rodax et al., 2021; TenHouten, 2018), an emotional mechanism, a process which transforms certain discrete emotions into others, or does it involve both? (2) Which emotions constitute the feeling of ressentiment, or drive it, and which emotions are its outcomes? (3) What are its stages and how do they engage with psychic defences? (4) How does social sharing consolidate its outcome emotions, values, and identities?

We make theoretical headway towards a conceptualization of ressentiment integrating seemingly independent but complementary approaches: The classic philosophical tradition (Nietzsche, 1885/1961; Scheler,
$1915 / 1961)$ with its contemporary proponents in philosophy and sociology (Aeschbach, 2017; Demertzis, 2020; Elster, 1999; TenHouten, 2018; Ure, 2014) highlight envy as the prime driver of ressentiment; sociological approaches (Scheff, 1994; Turner, 2007) focus on the repression and transmutation of shame and its social consequences; political psychology studies operationalise ressentiment as the affective driver of political reactionism (Capelos \& Demertzis, 2018); insights from psychoanalytical works elaborate on the workings of psychic defences (Bion, 1957; A. Freud, 1936; S. Freud, 1894; Klein, 1958, 1959; Kohut, 1984; Laing, 1961; Winnicott, 1971).

We begin with the nature of ressentiment as a complex emotion/sentiment, or an emotional mechanism (Section 2). We substantiate our definition of ressentiment as an emotional mechanism by identifying the emotions that are its drivers and its outcomes (Section 3). Following psychoanalytical studies on defences, we map out its four key stages (Section 4). We elaborate on social sharing and its consolidating but socially maladaptive function for the identity, emotions, and values of the ressentimentful individual (Section 5). In conclusion we discuss the implications of our contribution in understanding reactionary politics.

\section{Ressentiment: A Complex Emotion or an Emotional Mechanism?}

The categorization of ressentiment is an important question. Nietzsche and Scheler provide insightful suggestions on its nature: Nietzsche (1885/1961) tells us how ressentiment functions in a "man of ressentiment" and introduces transvaluation of the self and values as its core, driven by emotions of envy, humiliation, and inefficacious anger; Scheler (1961, p. 4) calls it "a self-poisoning of the mind which has quite definite causes and consequences." It is both a psychological "mechanism" relating to the transvaluation of desired but unattainable objects (Scheler, 1961, p. 65) and a "lasting mental attitude, caused by the systematic repression of certain emotions and affects" (Scheler, 1961, p. 4). For Scheler, the "ressentiment attitude" consists of "envy, the impulse to detract, malice, and secret vindictiveness... [that] have become fixed attitudes, detached from all determinate objects" (Scheler, 1961, p. 24). Such affective attitudes are interpreted as "sentiments" by Aeschbach (2017), who characterizes the latter as deeply rooted dispositions whose manifestations are emotions requiring a specific coherence and stability in the emotional episodes a subject is likely to feel. Yet both Nietzsche and Scheler understand ressentiment first and foremost as a psychological mechanism. Research in philosophy and social sciences has followed Scheler in identifying these two elements-psychological mechanism(s), and a sentiment-like pattern of certain emotions and attitudes-emphasizing either, or sometimes, similarly to Scheler, both (Aeschbach, 2017; Demertzis, 2020; Elster, 1999; Salmela \& von Scheve, 2017). 
Aeschbach (2017, p. 45) asks "whether or not ressentiment constitutes an emotion, a sentiment, a mechanism, or a psychological process of its own." Building on Scheler, he sees ressentiment as a temporally extended phenomenon with different sequences and therefore dissimilar to emotions:

The POR [person of ressentiment] first values something she cannot get which triggers a crushing experience and, in response to this first stage, she harbours hostile emotions directed against her existing or imagined rivals. A feeling of inferiority, although very characteristic, is not necessary; the fox for example is simply frustrated or experiences an unpleasant feeling of impotence. What is common to all cases however, and thus a necessary condition, is that the man of ressentiment eventually alters the value of what he cannot get or realise. We call this mechanism the reevaluation process and claim that it is a defining part of ressentiment. (Aeschbach, 2017, p. 93, italics by the author)

Aeschbach characterizes ressentiment as a reevaluation mechanism. At its core is the transvaluation of desired but unattainable objects, whose unattainability gives rise to unpleasant feelings of inferiority and impotence damaging the person's self-worth. Relating to value changes of this kind, Aeschbach (2017, p. 69) suggests "ressentiment is the very mechanism that transmutes envy into moral emotions such as resentment and indignation." Yet he also suggests ressentiment is an enduring "sentiment characterised by a series of object-specific dispositions that consolidate into a character trait [the vice of ressentiment] as the phenomenon progresses" (Aeschbach, 2017, p. 50).

As a sentiment, the manifestations of ressentiment are "hostile emotions (revenge, envy) as well as blaming attitudes (resentment, indignation)" that Aeschbach calls "ressentiment-emotions" (Aeschbach, 2017, p. 55). In this way, Aeschbach's analysis replicates Scheler's original view about ressentiment as a sentiment and a psychological mechanism. We agree an adequate account of ressentiment must include both elements, but their mutual relationship needs to be clarified in greater detail.

Demertzis (2020), following Scheler, approaches ressentiment as a "cluster emotion" or a "complex sentiment." He defines it as such:

An unpleasant complex moral sentiment with no specific addressees, experienced by inferior individuals including a chronic reliving of repressed and endless vengefulness, hostility, hatred, envy, and resentment due to the powerlessness of the subject in expressing them, and resulting, at the level of moral values, in the disavowal of what is unconsciously desired. (Demertzis, 2020, p. 132)
Emotions of this kind are constituents of ressentiment for Demertzis. Yet ressentiment is something else, for it develops only when "anger, envy, hostility, hatred and/or resentment... are incorporated and mutated into ressentiment insofar as the transvaluation process is put into motion initiated by the subject's incapacity to act out" (Demertzis, 2020, p. 136). Transvaluation has a crucial role in the development of ressentiment whose core meaning it constitutes for Demertzis. Yet even if the transvaluation is carried out by defences, their involvement does not turn ressentiment into a mechanism. Quite the contrary, Demertzis argues "the transvaluation process is in itself a configuration of defence mechanisms and therefore it seems to me that it confers no added value by dropping ressentiment out from the list of emotions" (Demertzis, 2020, p. 133). The logic of this argument is that since ressentiment is brought about by psychological mechanisms, it cannot be a mechanism itself. However, this is a non sequitur. This view of ressentiment as a complex or cluster emotion generates more questions than answers.

First, it leaves the relationship between ressentiment and its constituent emotions unexplained. In what sense are emotions such as anger, envy, hostility, hatred, and resentment constituents of ressentiment if they must be incorporated and mutated in order to become ressentiment? Once incorporated and mutated by repression and transvaluation, what is left of the emotions that constitute ressentiment? If these emotions lose their discrete identities and are amalgamated into ressentiment that is something different, the other emotions appear to be ingredients of ressentiment rather than its constituents. Alternatively, those emotions can be manifestations of ressentiment if the latter is understood as a sentiment, a higher-order affective attitude that manifests as thematically related emotions and attitudes, as Aeschbach (2017) suggests. However, this interpretation leaves the incorporation and mutation of the emotions that manifest ressentiment in Demertzis' view redundant or mysterious. What is the function of these processes if the emotions supposed to undergo those processes in becoming ressentiment remain its manifestations?

Problems with ressentiment as a complex emotion are also evident in TenHouten (2018). He argues that ressentiment and resentment are two forms of the same "tertiary-level" emotion, "whose primary emotional components are anger, surprise, and disgust, and whose secondary emotional components are contempt, shock, and outrage" (TenHouten, 2018, p. 6). Resentment is an active and forceful emotion, whereas ressentiment is its passive and helpless shadow. This distinction between resentment and ressentiment is consistent with Nietzsche and Scheler, but also in tension with the view that resentment and ressentiment are ultimately the same "tertiary emotion" with the same constituent emotions. A widely accepted philosophical criterion is that discrete emotions have a distinct "formal object" (Kenny, 1963) or "core relational theme" (Lazarus, 1991)-an 
evaluative property or content that particular instances of the same emotion type ascribe to the intentional object of emotion, an event, situation, person, etc. For instance, the formal object of fear is the evaluative property of "being dangerous" that particular instances of fear ascribe to their targets. If resentment and ressentiment are forms of the same emotion, they should have the same formal object or core relational theme. Yet, there is a wide agreement among researchers of ressentiment that whatever it is, it differs from resentment, usually understood as moral anger at injustice (e.g., Aeschbach, 2017; Demertzis, 2020; Meltzler \& Musolf, 2002; Ure, 2014). The involvement of transvaluation and the defences carrying it out in ressentiment (but not in resentment) make it conceptually difficult to defend a view of ressentiment and resentment as two forms of the same emotion. This difference renders problematic TenHouten's view that ressentiment and resentment have the same constituent emotions: anger, disgust, and surprise. This is a speculative view leaving the roles of disgust and surprise unclear.

With the above concerns in mind, we make the following propositions: Ressentiment is best understood as a psychological mechanism that produces and reinforces a sentiment-a disposition to have certain thematically related emotions and attitudes. Emotional mechanisms have four conditions: (1) emotional dissonance; (2) reappraisal; (3) change in the emotional response; and (4) disposition of the emotional outcome to be collectivized (Salmela \& Salice, 2020). We extend this account analysing the functioning of reappraisal in terms of psychodynamic defences transmuting the self and its values. The proposed view integrates the two main elements of ressentiment in extant literature providing a causal account of their mutual relationship. It explains the dynamic character of ressentiment better than the other views whose insights it also incorporates.

Agreeing with other scholars, we identify the axis of ressentiment as victimhood (Aeschbach, 2017; Hoggett, 2018; Katsafanas, in press; Nietzsche, 1885/1961; Rodax et al., 2021; Ure, 2014). A powerless sense of victimhood may belong to inefficacious anger and envy where the individual feels deprived, depleted, and inferior. An analogous powerless victim position also belongs to shame, in which the subject attacks the self. This attack on the self, if enduring, is so painful that the victimizer needs to be externalized. To evade mental pain emerging from negative feelings targeting the self, in ressentiment the self-reproaching victim position is transformed into a morally superior victim position providing justification for the other-directed moral emotions of resentment, indignation and hatred, as well as a foundation for the formation of collective identities of victimhood.

Breaking with other scholars who see ressentiment as an objectless emotion, not specifically about something or someone (Demertzis, 2020), we identify two objects of ressentiment: (1) the self, elevated from low to high; and (2) the value of what one wants to have (desired object in envy and anger) or to be (aspired roles or identities in shame) reversed to undesired and unwanted. Aeschbach (2017, p. 94) calls value change of this kind a "strong ressentiment," as distinct from the "weak ressentiment" that merely denounces the value of an unattainable particular object (such as particular sweet grapes), without leading to a reversal in values. He also observes, following Poellner (2011), that transvaluation allows the subject to feel moral superiority, instead of feeling inferior and impotent. However, neither Poellner nor Aeschbach see the self as an object of ressentiment besides values, as we do.

We also identify two objectives of ressentiment: (1) to change the self and its values (through transvaluation); and (2) to maintain the "new self" and "new values" and emotions through social sharing. Although attention has been provided to achieving transvaluation through defences (see Demertzis, 2020, p. 138), the second objective is novel and under-theorised. The powerless self in ressentiment comes to feel superior and powerful. This constitutes a reversal where the self changes from worthless and incapable to pious and elevated. This change requires the employment of defences and goes beyond the improvement of self-esteem by ressentiment on which previous philosophical research focuses (Aeschbach, 2017). We argue the self is transmuted in ressentiment: With transvaluation, an individual's identity becomes disconnected from one's sense of who one is, generating a "fragmented self," broken in two: an old (painful) self, tucked away, and a new (elevated) self, accepted as the "all-good" self. This outcome is similar to what Winnicott (1965, p.140) describes as a "false-self." Through social sharing, this "new self" is maintained and reinforced. Thus, we argue, the core objectives of ressentiment are to change its very subject and maintain its change.

If ressentiment involves repression, reaction formation, splitting, regression, and denial (e.g., Aeschbach, 2017; Demertzis, 2020; Hoggett, 2018; Scheler, 1961), it is worth focusing on how psychic defences are employed throughout this mechanism, how they relate to the thoughts and feelings serving as triggers, the evaluations of the self, prior to and after its transvaluation, the transmutation of its values, the maintenance of the "new self," as well as to ressentiment outcomes. It helps to introduce a few key properties of defences. They are internal, complex, and (mostly) unconscious regulatory processes of resisting/defending against mental frustrations, stress, and conflict; they alter perceptions of the self, the other(s), thoughts, and feelings (A. Freud, 1936; Vaillant, 1994). Psychologists agree that any mental function (cognition, affect, and conation) can be used defensively, and everyone needs and uses defensive manoeuvres against mental pain at particular times (Kernberg, 1976; Vaillant, 1994). We argue that defences provide the analytical framework to consider ressentiment as an emotional mechanism available to all individuals without pathologizing or stigmatizing its use. 
Our systematic analysis of defences expands on scholars who see their value in relation to ressentiment and provides a framework that unpacks their function within this emotional mechanism.

Finally, our model theorises four stages of ressentiment. First, the "triggering stage" involves the negative emotions with feelings of inferiority and/or impotence as affective drivers of ressentiment. Experienced as repeated assaults on the individual's self-esteem, they compromise ego-strength and lead to diminished capacity for adaptive psychic resistance. Second, the "initiating stage" involves failed adaptive defences and regression, followed by the adoption of partially adaptive or maladaptive defences prior and en route to transvaluation. Third, the "advancing stage" involves maladaptive defences delivering the transvaluation of the self and the values. The outcomes of this stage are the sentiments of "general negativism" (Scheler, 1961, p. 21) manifesting as emotions of resentment, indignation, and hatred, and as an anti-stance of rejection towards objects perceived as injurious or insulting, and the "new values" and a "new self" as a precarious identity. Fourth, the "consolidating stage" involves defences strengthening the transvaluation and the fragmentation of the self through social sharing, preventing relapse to the "old self" and the "old values" while bringing its outcomes into the political sphere.

\section{Affective Drivers and Outcomes of Ressentiment}

Viewing ressentiment as a psychological mechanism we distinguish between affects and emotions that are its triggers and outcomes, building a causal argument into the affective elements of ressentiment. Previous accounts suffer this shortcoming, beginning with Scheler's view of its elicitors:

Revenge, envy, the impulse to detract, spite, Schadenfreude, and malice lead to ressentiment only if there occurs neither a moral self-conquest (such as genuine forgiveness in the case of revenge) nor an act, or some other adequate expression of emotion (such as verbal abuse or shaking one's fist), and if this restraint is caused by a pronounced awareness of impotence. (Scheler, 1961, p. 6)

Importantly, revenge and the impulse to detract are not emotions but rather action tendencies of other emotions-anger and envy, respectively. Scheler observes the desire to revenge is "preceded by an attack or an injury" with the "accompanying emotions of anger and rage" whose immediate reactive impulse is "temporarily or at least momentarily checked and restrained" due to "the reflection that an immediate reaction would lead to defeat, and by a concomitant pronounced feeling of 'inability' and 'impotence'" (Scheler, 1961, p. 5). Elsewhere he writes: "There is a particularly violent tension when revenge, hatred, envy, and their effects are coupled with impotence. Under the impact of that tension, these affects assume the form of ressentiment" (Scheler, 1961, p. 20).

Scheler thinks ressentiment emerges whenever the subject of a negative emotion is incapable of either acting on the emotion or even expressing it, thereby "discharging" the emotion. The situations in which inability of this kind leads to ressentiment are "lasting situations which are felt to be 'injurious' but beyond one's control-in other words, the more the injury is experienced as a destiny" (Scheler, 1961, p. 8). Scheler also observes that "this psychological dynamite will spread with the discrepancy between the political, constitutional, or traditional status of a group and its factual power" (Scheler, 1961, p. 7), when members of a social group or class experience a status loss in society. Salmela and von Scheve (2017) note that the threat of a status loss can trigger the same psychological processes as an actual loss. From this perspective, experiences of impotence and inferiority resulting from emotions felt as injuries or insults are perhaps more important drivers of ressentiment than the identity of particular emotions to which these feelings associate.

Even so, it seems some emotions fit this role better than others. Scheler highlights two sources of ressentiment: the desire for revenge on the one hand, and envy, jealousy, and competitive urge on the other. We have already observed revenge is an action tendency of anger rather than an independent emotion. More specifically, Scheler speaks of an inefficacious anger whose action tendency of revenge must be repressed, with ensuing feelings of impotence and powerlessness. Envy and jealousy involve these feelings as part of their phenomenology, as they are experienced when another person has something we covet (envy), or threatens to rob us from something we possess (jealousy). Scheler specifies that envy "leads to ressentiment when the coveted values are such as cannot be acquired and lie in the sphere in which we compare ourselves to others" (Scheler, 1961, p. 9). He observes that constant comparisons elicit and reinforce "oppressive feelings of inferiority" exacerbated by the "system of free competition" in society. Therefore:

Ressentiment must be strongest in a society like ours, where approximately equal rights (political and otherwise) or formal social equality, publicly recognized, go hand in hand with wide factual differences in power, property, and education. While each has the "right" to compare himself with everyone else, he cannot do so in fact. (Scheler, 1961, pp. 7-8).

Even if Scheler wrote these words over a century ago, his analysis strikes one as surprisingly timely. The contemporary liberal "rhetoric of rising" promises success to everyone who, with an equal chance, works hard to develop one's skills and talents. However, not everyone can win, and individuals can blame only themselves if they lose in the competition for meritorious positions, with resulting 
feelings of humiliation and resentment (Sandel, 2020)two emotions that we recognize as a driver and an outcome of ressentiment.

Another possible driver of ressentiment along with envy is shame (Salmela \& von Scheve, 2017). Shame is felt when the subject fails to live up to, or even minimally exemplify in behaviour, an important personal value often shared with others as a core constituent of a valued identity, such as a parent or partner or professional (Deonna et al., 2012; Salmela, 2019). Importantly, whereas in envy it is possible to denounce the value of a particular object without denouncing the value itself, thus engaging in only "weak ressentiment," shame by default comes with "strong ressentiment" because the only way to avoid it is to change one's values. Similar to envy, shame involves feelings of impotence, inferiority, and powerlessness. Moreover, shame is a stigmatized emotion in Western cultures where it is framed as deviant, despised, socially undesirable, and therefore inexpressible, associated with weakness, inferiority, defeat, and low status (Lewis, 1995; Walker, 2014). Due to the painfulness of shame and its strongly negative implications on the self, we are motivated to avoid and repress it, with the consequence it turns into anger (Lewis, 1971; Scheff, 1994; Turner, 2007). Finally, shame is another key emotion besides envy in competitive, meritocratic societies. "When individuals cannot meet expectations in encounters lodged in key institutional domains or are negatively sanctioned in these encounters, it is likely that they will experience shame" (Turner, 2007, p. 517). Turner argues shame felt in different institutional domains crops up and intensifies, increasing the pressure towards repression.

Having identified envy, shame, and inefficacious anger (and their adjacent feelings of impotence, inferiority and powerlessness that hurt the vulnerable self) as the affective drivers of ressentiment, the next question is which emotions are its outcomes. Scheler thinks ressentiment does not change the type of a repressed emotion so much as its intentionality from a locally focused emotion into a globally dispersed affective attitude. His example is conscious hatred of a particular person that through repression turns into a general negativism:

[A repressed emotion] becomes more and more detached from any particular reason and at length even from any particular individual. First it may come to bear on any of my enemy's qualities, activities, or judgments and on any person, relation, object, or situation which is connected with him in any way at all. The impulse "radiates" in all directions. At last it may detach itself even from the man who has injured or oppressed me. Then it turns into a negative attitude towards certain apparent traits and qualities, no matter where or in whom they are found....When the repression is complete, the result is a general negativism - a sudden, violent, seemingly unsystematic and unfounded rejection of things, situations, or natural objects whose loose connection with the original cause of the hatred can only be discovered by a complicated analysis. (Scheler, 1961, p. 21)

We suggest "general negativism" here is best understood as a sentiment manifesting as other-directed negative emotions such as anger and hatred as well as an anti-stance of rejection towards various things and objects perceived as insulting or injurious. The dissociation of qualities from the original objects of emotion and their re-association with other objects after repression explains how Scheler is able to talk about anger and hatred both as drivers of ressentiment and as its outcomes.

There are reasons to believe anger and hatred are, similarly to resentment and indignation, more often outcomes of ressentiment than its drivers. None of these emotions-inefficacious anger excluded-involves the feelings of impotence, powerlessness and inferiority we have identified as central to the phenomenology of the drivers of ressentiment. By contrast, they involve the perspective of moral superiority or righteousness, even when the subject is incapable of removing the felt "injury" or "injustice" by acting on and/or expressing the emotion, as is the case in hatred (see Aeschbach, 2017). There is evidence that hatred emerges through consecutive instances of anger in which the subject perceives he or she is not capable of influencing the insulting behaviour of the target of emotion which in hatred is appraised as immoral, malicious, and incapable of change (Fischer et al., 2018; Halperin, 2008; Salice, 2020; Szanto, 2019). Aeschbach (2017, pp. 146-153) observes that blaming others allows the person of ressentiment to discharge and express the repressed hostile emotions, especially envy, in the form of moral emotions, resentment and indignation, which also counterbalance a damaged sense of self-worth with positive feelings of moral superiority.

Yet the new values of a person of ressentiment rest on self-deception, which maintains a tension and the need to reinforce the new values and the associated emotions, again and again. Scheler and his philosophical interpreters typically explain this tension by adopting a realist view of values as objectively existing qualities perceivable by an intuitive faculty these theorists call "value feeling" (Wertfühlen). Irrespective of whether a mental act of this kind is possible, and whether there are mindindependent values in the first place, we suggest an alternative explanation to the tension and vacillation in the emotions of a person of ressentiment, drawing from psychoanalytic theorizing on defences while detailing the mechanism of ressentiment across four stages.

\section{The four Stages of Ressentiment: Psychic Economy and Defences}

In our model, the triggering, initiating, advancing, and consolidating stages of ressentiment have idiosyncratic 
duration and contain specific defences depending on an individual's psychic capacities. We approach defences as a toolset individuals employ to deal with mental pain. The combination of defensive coping strategies individuals adopt is idiosyncratic and depends on their levels of ego-strength and identity integration at that particular time in their lives (Cramer, 1991).

Ego-strength refers to one's psychic capacity to transcend impulsive action, develop self-control and selfreflection, overcome one's illusions, cope with stress and resolve conflicts (Carveth, 2018; A. Freud, 1936). Because ego-strength helps individuals maintain a cohesive sense of self-identity, it is directly linked to identity integration. Lack of ego-strength (i.e., ego-deficit) can display as self-deception, difficulty with reality testing, lack of cohesive identity, and emotion dysregulation (Erikson, 1959; A. Freud, 1936; Vaillant, 1993). It follows that the defences individuals adopt have a psychic cost expended in order to sustain them, or these defences break down; furthermore, individuals' efforts to sustain particular defences can overtime compromise ego-strength (A. Freud, 1936; S. Freud, 1894). High ego-strength is associated with the deployment of adaptive (mature, high order) defences which promote self-realization. These are the "good mental coping habits" (like creativity, humour, altruism, and sublimation) enhancing psychosocial development. Although individuals cope the best they can, some coping habits can be destructive. Maladaptive (immature, low order) defences are the "bad mental coping habits" which provide comfort through self-deception and distortion of reality, can turn the individual against itself, and can be socially unacceptable (Cramer, 1991; Erikson, 1959; A. Freud, 1936; Klein, 1958; Vaillant, 1993). The above invites us to consider the psychic economy of ressentiment by focusing on the ego-strength capacities of individuals, and identify the defences which can fend off ressentiment and those which advance it.

The triggering stage involves repeated experiences of deprivation, loss, and failure resulting in frustration. But these do not necessarily lead to ressentiment. We argue individuals have the psychic capacity to manage frustrations and negative emotions through adaptive defences when their ego-strength is high. Sublimation, humour, altruism, and suppression are (mostly) conscious processes regularly employed by individuals to alleviate suffering by deflecting stress and mitigating unresolved conflicts (Cramer, 2015). Because these defences strengthen the emotional integrity of the individual and are liberating from mental pain, they are associated with adaptive functioning. We expect the self-reproaching feelings of inferiority or impotence to not be pronounced, the frustrating event to not be perceived primarily as an attack to the self, and ressentiment to be fended off, when frustration and mental suffering can be sublimated, temporarily suppressed, or addressed with humour.

The initiating stage starts with failing to deal with conflict-generating realities, either because ego-strength is depleted and adaptive defences break down, or because an underdeveloped self cannot deploy adaptive defences in the first place. The first step is a psychic regression, a return to a vulnerable psychological state. According to A. Freud (1936) when individuals regress, mental pain takes the form of anxiety, depression, fear, anger, envy, shame, pining. We note that envy, shame, and inefficacious anger, the emotional foundations of the victimhood axis, present repeated failures as attacks to the self, making the possibility of a positive outcome untenable. We argue that in the initiating stage defences aim to mentally bypass the negative affects by distorting facts and reality. Individuals engage in ressentiment not because of a pathological need or malevolence, but because they seek to rid themselves from the emotional pain caused by feelings of impotence and inferiority, and the embarrassing thoughts of the self as unworthy. In essence, ressentiment aims at ending this repetition of failure and its associated feelings through transvaluating. In this stage, we identify affective and cognitive defensive manoeuvres whereby the individual (1) dislocates negative affects from cognitions and evaluations that feed those affects (through repression of affect and isolation/dissociation), and (2) reattaches these affects to other cognitions and evaluations (through displacement/substitution and reaction formation/reversal).

"Dislocation defences" in ressentiment involve the repression of affect and the dissociation of cognitions. Repression targets emotions, preventing from making conscious the disturbing feelings attached to frustrating thoughts (memories, wishes, ideas). Repression requires ego-strength to be maintained and when it breaks down, "the return of the repressed" manifests as generalised anxiety, dysfunctional behaviour or somatization (A. Freud, 1936). Scheler (1961, p. 49) argues that ressentiment contains the repression of the vindictiveness and the repression of the imagination of vengeance, while Demertzis (2020) notes the repression of the object of desire (p. 127), and the repression of negative emotions (p. 133). Dissociation/isolation targets cognitive elements, whereby the individual isolates frustrations in one aspect of their life or the self, leaving other aspects relatively unscathed (Freud, 1936). The value of dissociation is acknowledged in ressentiment (Demertzis, 2020). By placing the thoughts of one's inability to attain a goal in separate mental compartments not allowed to meet, the ressentimentful individual expends ego-strength to avoid dealing with mental pain.

"Reattachment defences" in ressentiment involve displacement and reaction formation. Displacement (substitution) of affect redirects negative affect to a more acceptable object, either outward towards an external object (generating anger), or inward towards the self (generating shame) when it is not possible to displace outward. The original object is substituted outward with an external object or substituted inward with the self (A. Freud, 1936). Several scholars highlight the impotence and weakness of those who turn their negative 
affect, related to their repeated failure, towards a weaker target (Aeschbach, 2017; Demertzis, 2020; Nietzsche, 1961; Scheler, 1961; Ure, 2014). We make a distinction here between this short-lived displacement of negative affect at available surrogate objects experienced in this initiating stage of ressentiment vs. the chronic and vengeful resentment at any scapegoats perceived as fundamentally evil and/or persecutory, present at the advancing stage of ressentiment. This, we think corresponds to the "weak vs. strong ressentiment" distinction by Aeschbach (2017).

Reaction formation, another reattachment defence, blends the repression of the original rejected affect or desire, with the exaggeration of its direct opposite. The individual no longer feels anxious, but confident; it is not uncertain, but certain; it is not weak, but strong. The value of reaction formation in ressentiment is already acknowledged (Demertzis, 2020), however we note a crucial point: Its exaggerated affective opposition can be expressed as intense antipathy towards the coveted and unattainable object (in envy) or one's valued identity (in shame), but also as intense preoccupation with this object or identity, to overcompensate for hatred towards it. We argue this less appreciated function of reaction formation noted by Freud (1936) is the reason behind the almost obsessive preoccupation of the ressentimentful individual with victimhood: The original rejected emotions (anxiety, feelings of impotence, powerlessness, worthlessness) are repressed but persist unconsciously, and exaggeration is accompanied by compulsive preoccupation with the unattainable object or identity. While reaction formation aims at the disavowal of the desired object or valued identity, it actually feeds feelings of injury and worthlessness.

Rationalization is another defensive manoeuvre and involves the cognitive distortion of facts to make a failure less threatening. In ressentiment, the fox explains its failure to reach the grapes because the ground is too soft, or the vine too high. The grapes' value is not altered yet, but the rationale of the failure is comfortably reinterpreted. This defence is achieved by inventing seemingly plausible reasons why something happened, and in ressentiment it can create a cycle of self-deception, not addressing the original problem, but mitigating its frustration (Aeschbach, 2017, p. 161).

The short-term advantage of these largely unconscious and partially adaptive defences is that they find side ways to deal with conflict and mental pain. Their long-term cost is that they compromise individuals' capacity to adapt to reality (S. Freud, 1894). We argue that these defences can delay the advancement of ressentiment for individuals with sufficient egostrength, if adopted short-term. If adopted long-term, these defences can turn maladaptive and erode egostrength further, because they do not allow individuals to see the issues they face. This is where we identify the transition between the initiating stage that displays as "weak ressentiment," and the advancing stage that displays as "strong ressentiment." For as long as partially adaptive defences can be sustained as "temporary fixes," making use of ego-strength capacities, the mechanism of ressentiment remains initiating. The mental pain, temporarily evaded, periodically returns compromising the individual's ego-strength. Our developing argument is that when ego-strength is eventually depleted, these defences collapse, and ressentiment moves to its next stage.

The advancing stage of ressentiment engages the transvaluation, offering a long-lasting, even chronic, way around the frustrating conflicts. The "old self" is denied (imagine the fox claiming it was never a weak/impotent fox; rather it renounced its pursuit on its own free will); what was valued in the coveted object or one's identity is denied (the grapes were always sour, only losers want these grapes); the "new self" and the "new values" are now "all good" and those perceived as responsible for the failures of the "old self" are "all bad." These are signs that the ressentimentful individual has lost the ability to engage with internal and external objects as "whole" (having both good and bad aspects). The ressentimentful individual holds the firm belief these "spiteful others" are aggressive, hostile, and vengeful, they feel hatred, destructive envy, and anger. In response the ressentimentful individual feels a strong sense of injustice and hypervigilance in its morally elevated victimhood.

In the above, we identify the denial of facts, splitting, and projection, defences which are considered developmentally simple and cognitively undemanding (A. Freud, 1936). When ego-strength is weak or depleted, it is possible to sustain defences which require fewer psychic resources (Klein, 1958). The denial of facts (to be distinguished from repression of affect) is a simple psychic manoeuvre involving the negation of a fact by employing a fantasy. Splitting (Klein, 1959) involves the simplification of reality into all-bad and all-good objects. Adaptive and developmentally essential in infancy, splitting is problematic in adult life which presupposes the recognition the world and the self are not "only good" or "only bad" (Klein, 1958). Simply put, as one matures, one gradually learns to engage with objects as whole (having both good and bad aspects) and tolerate the ambivalent feelings (e.g., love and hatred) one experiences when relating to others. The ressentimenful individual, we argue, splits the world into "only good" or "only bad" parts, failing to relate to itself and to others as whole objects. In this stage, we also see projection as responsible for the persecutory anxiety of the ressentimentful individual, which is deeper than the temporary venting of one's anger by blaming weak targets (the displacement defence in the initiating stage). Studies in psychology outline the key feature of projection: All the bad and painful for the self is projected out (Bion, 1957; Klein, 1959). When the bad parts of the ressentimentful self are seen in "the other," the ressentimentful individuals feel they are not hateful or hostile; the "others" are.

As the advancing stage completes, we see the first stage of "ego-fragmentation": The ressentimentful 
individual is isolated from its sense of self, its original values, and the conflict-generating reality. The employed maladaptive defences impair one's ability to relate to one's self and the world by compromising reality testing. Thus, we argue, ressentiment offers a solution, not a resolution: The individual has no other means of dealing with its already compromised vision of psychic reality but avoiding it, unable to confront it, or resolve it. The originally impotent self is replaced by an "all-good new self" and what was valued in the unattainable object or one's valued identity is compensated by new values. Whereas in the initiating stage partially-adaptive defences provide temporary solutions, in the advancing stage, through transvaluation, we see the radical and long-lasting distortion of an inconvenient and painful reality.

Ressentiment is not complete until the consolidating stage, whereby "ego-fragmentation" and the outcomes of transvaluation are sustained through social interactions with peer-others. We note that such social interactions have a dual function: They regenerate psychic capacities through validation and confirmation, providing resistance to the return of the repressed, and offer recurrent opportunities to displace old and new envy and frustrations onto enemy-others. Adding to scholars who see social sharing as the opportunity to validate substituted values (Latif et al., 2018; Posłuszna \& Posłuszny, 2015; Salmela \& von Scheve, 2017), we stress that social sharing also, and primarily, validates the "new self" through mirroring and idealizing in the interactions with peer-others.

Studies in psychology identify idealization and mirroring as two central needs towards psychic development (Kohut, 1984; Winnicott, 1971) and note how relationships with peers serve as an "identity kit" in social interactions (Laing, 1961, p. 70). We see important parallels when the ressentimentful individual comes in contact with peer-others: Mirroring provides recognition and reinforces the superficial "new self" feeling pride rather than shame, satisfaction rather than disappointment, being somebody rather than nobody, counting for something rather than nothing. We argue that, in this stage, defences of introjection and projection are in a steady feedback loop, reinforcing the establishment of the "new self" and maintaining "ego-fragmentation."

With introjection, the idealised "all-good" peerothers are taken in the "new self" in an illusion of superiority. We argue that the ressentimentful individual, unable to have a realistic appreciation of the peers and the self seen as "part-good, part-bad," feels depleted in self-comparison with the "all-good" peers. We use the concept of "unconscious envy" borrowing from Klein (1958). We theorise that the ressentimentful individual, perceiving the peers as "all-good" providers of "goodness" by association, experiences anxiety of not being "as good" as them.

Furthermore, this "all-good, all-bad" comes in moral terms and reinforces the identity of righteous victimhood experienced in ressentiment (Hoggett, 2018).
However, we suggest an identity based on victimhood is hollow insofar as it is founded on the precarious "new self." Therefore, when the sharing of a collective identity of victimhood stops, the ressentimentful individual loses the mirrors giving it a reference point and experiences the mental pain of feeling again worthless and alone.

\section{Beyond the Self: The Political Implications of Bonding Through Ressentiment}

Social sharing of the transformed values and emotions reinforces them providing a sense of warrant or objectivity (Smith et al., 2007). It also facilitates the emergence of other shared emotions such as group pride and feelings of togetherness, supporting social cohesion and solidarity within the group bonded by ressentiment. To share an emotion, its intentional target typically has to be generalized. Thus, resentment, anger, or hatred emerging from ressentiment, target groups whose members are perceived to possess common negative characteristics, or target individuals (political leaders, celebrities) associated with such groups. Scheler observes negative attitudes towards traits and qualities are detached from their original targets and become attached to targets of negative attitudes wherever they are found. Scheler also recognizes the importance of social sharing in ressentiment. However, it is Nietzsche who emphasizes the role of social sharing most among both classic and contemporary theorists of ressentiment (yet see Katsafanas, in press):

All the sick and sickly strive instinctively for a herdorganization, out of a longing to shake off dull lethargy and the feeling of weakness: the ascetic priest senses this instinct and promotes it; wherever there are herds, it is the instinct of weakness that has willed the herd and the cleverness of the priests that has organized it. For it should not be overlooked: the strong are as naturally inclined to strive to be apart as the weak are to strive to be together. (Nietzsche, 1885/1961, pp. 100-101)

Nietzsche argues the ascetic priests regulate the emotions of the ressentimentful individuals. Priests direct hatred and vengefulness towards "the rich, the noble and powerful," claiming "you are eternally wicked, cruel, lustful, insatiate, godless, you will also be eternally wretched, cursed and damned!" (Nietzsche, 1885/1961, p. 17). Priests also make the weak and suffering individuals blame themselves for their condition by inventing $\sin$ as an explanation for their suffering and guilt as an emotional antidote to $\sin$. This way, priests are invaluable regulators of the emotions emerging from ressentiment.

We see structurally similar dynamics in contemporary reactionary political movements driven by ressentiment: blaming scapegoats such as political and cultural elites, immigrants, refugees, the long-term unemployed, for the victimization of the ingroup; turning 
ressentiment-mediated moral emotions of anger, resentment, and hatred towards these groups; the influence and suggestion of charismatic leaders whose affective rhetoric effectively contributes to their supporters' emotion regulation (Kazlauskaite \& Salmela, 2021; Salmela \& von Scheve, 2017). Sharing of other-directed negative emotions in social interaction reinforces and validates these emotions. It also gives rise to positive collective emotions such as pride and moral righteousness about shared victim identities of those united in anger and resentment (Turner, 2007). Shared moral emotions are empowering, and remaining feelings of inferiority and powerlessness can be refashioned as manifestations of moral victimhood. When collective pride comes with prejudice and hostility towards outgroups, it qualifies as hubristic (Sullivan \& Day, 2019), and promotes collective narcissism (Golec de Zavala et al., 2009). This link between collective narcissism and ressentiment is explored in Capelos et al. (2021).

A similar dynamic applies to hatred emerging from repressed inefficacious anger: the interpretation of hatred as group-based allows its sharing. This may explain why hatred tends to generalize to groups even if it would originate from individual-level anger. Collectivization of hatred is so common, several authors have argued it to be the paradigmatic type of hatred (see, e.g., Szanto, 2019). Moreover, shared hatred reinforces the collective identity of victimhood and the associated feelings of togetherness, rendering the experience of shared hatred predominantly, if not entirely, pleasant. In the contemporary world, emotional sharing may occur offline and online as social media offers venues for cultivating collective anger, hatred and positive collective emotions about shared social identities.

\section{Conclusions}

We have argued ressentiment is an emotional mechanism centred on victimhood and has two objects: the self and the unattainable object or one's valued identity. The function of ressentiment is the evasion of mental pain emerging from negative feelings targeting the vulnerable self through transvaluation of the self from inferior, failing, a loser, into a noble, pious, and superior victim, and of an unattainable object or valued identity into an undesired one. In these transvaluations, ressentiment employs largely idiosyncratic defences depending on the individual's ego-strength. Ressentiment is driven by envy, shame, and inefficacious anger, with their associated feelings of inferiority and impotence. With a transvaluation these negative emotions are projected towards "all-bad" others in the form of resentment, indignation, and hatred, and are reinforced and validated by social sharing and introjection of "all-good" peers.

We understand the combination of defences in ressentiment as a "corkscrew," its helix gripping into the layers of an injured and poorly integrated self. $A$ response to real frustrations and unbearable suffer- ing, ressentiment has a high cost for the individual in the long run as it does not provide actual fulfilment through resolution of the original problems. The ressentimentful individual cannot tolerate frustrations, maintain hope, bear delays in gratification, acknowledge the disjunction between reality and self-deception, recognize oneself and others as both good and bad, and avoid despairing. The corkscrew of ressentiment produces individuals whose psychology brings to mind the words of Laing (1961, p. 133): "With no real future of their own, they may be in that supreme despair which is, as Kierkegaard says, not to know they are in despair."

We end by elaborating the political implications of ressentiment. This emotional mechanism constitutes the affective core of reactionism, a long-lasting political orientation bundling anti-preferences, resentful affect, and the desire to break away from the present and reinstate a status quo ante (Capelos \& Demertzis, 2018; Capelos \& Katsanidou, 2018), what Bauman (2017) called "Retrotopia." Ressentiment is key for understanding reaction: It transforms citizens' conventional right or left political orientations to backward-oriented values, which can be expressed as anti-preferences, intolerance towards outgroups and minorities, and dormant support for illegal and violent actions (Capelos \& Demertzis, 2018; Capelos et al., 2017; Godwin \& Trischler, 2021; Mayer \& Nguyen, 2021; Sullivan, 2021).

Besides motivating hostility towards outgroups (Kiss, 2021; Sullivan, 2021), ressentiment constitutes a volatile basis for ingroup dynamics. The ressentimentful individual has hollow peer relationships, seeking peers' recognition of the "new self" while defensively suspecting them. Since the desire for recognition is important, the suspicion remains latent and unconscious, to avoid being torn between opposite motives. Still the suspicion is there, corroding the twinship bond of ressentiment. We see its manifestations in reactionist political movements whose interpersonal bonds flare up into bitter feuds between fractions whose members accuse each other as traitors of the common cause. The ease in which these abrupt and violent rifts emerge indicates the latent suspicion of others is dormant. Gronfeldt et al. (2021) highlight the propensity of collective narcissists to sacrifice in-group members to defend the image of their group, and Szanto (in press) identifies phenomena of "fraternity-terror" and internal threat in fanatics' groups. These findings beg further exploration and can be illuminated by the systematic understanding of the emotional mechanism of ressentiment in the context of grievance politics.

\section{Acknowledgments}

We thank the anonymous reviewers of Politics and Governance, whose comments on an earlier version of this manuscript allowed us to improve it significantly. We also thank Madeleine Provost for her generous help in proofreading our work. Salmela's work was supported by funding from the European Research Council (ERC) under 
the European Union's Horizon 2020 research and innovation programme (grant agreement no. 832940).

\section{Conflict of Interests}

The authors declare no conflict of interests.

\section{References}

Aeschbach, S. (2017). Ressentiment-An anatomy [Doctoral thesis. University of Geneva]. Archive Ouverte UNIGE. https://doi.org/10.13097/archive-ouverte/ unige: 103621

Bauman, Z. (2017). Retrotropia. Polity Press.

Betz, H. G. (2005). Against the system: Radical right-wing populism's challenge to liberal democracy. In J. Rydgren (Ed.), Movements of exclusion: Radical rightwing populism in the Western world (pp. 25-40). Nova Science Publishers.

Bion, W. R. (1957). Differentiation of the psychotic from the non-psychotic personalities. International Journal of Psychoanalysis, 38, 206-275.

Capelos, T., \& Demertzis, N. (2018). Political action and resentful affectivity in critical times. Humanity \& Society, 42(4). https://doi.org/10.1177/01605 97618802517

Capelos, T., \& Katsanidou, A. (2018). Reactionary politics: Uncovering the psychological roots of 'anti' preferences in European integration and immigration debates. Political Psychology, 36(9), 1271-1288.

Capelos, T., Katsanidou, A., \& Demertzis, N. (2017). Back to black: Values, ideologies, and the black box of political radicalization. Science and Society, 35, 35-68.

Capelos, T., Salmela, M., Sullivan, G., \& Chrona, S. (2021). Ressentiment, collective narcissism, and conservation values [Paper presentation]. HEPP 2 Conference, Helsinki, Finland.

Carveth, D. L. (2018). Psychoanalytic thinking: A dialectical critique of contemporary theory and practice. Routledge.

Celis, K., Knops, L., Van Ingelgom, V., \& Verhaegen, S. (2021). Resentment and coping with the democratic dilemma. Politics and Governance, 9(3), 237-247.

Cramer, P. (1991). The development of defense mechanisms: Theory, research and assessment. Springer.

Cramer, P. (2015). Understanding defense mechanisms. Psychodynamic Psychiatry, 43, 523-552.

Demertzis, N. (2020). The political sociology of emotions. Essays on trauma and ressentiment. Routledge.

Deonna, J., Rodogdo, R., \& Teroni, F. (2012). In defense of shame. Oxford University Press.

Elster, J. (1999). Alchemies of the mind. Cambridge University Press.

Erikson, E. (1959). Identity and the life cycle. Psychological Issues, 1(1), 50-100.

Ferrari, D. (2021). Perceptions, resentment, economic distress, and support for right-wing populist parties in Europe. Politics and Governance, 9(3), 274-287.
Fischer, A., Halperin, E., Canetti, D., \& Jasini, A. (2018). Why we hate. Emotion Review, 10(4), 309-320.

Freud, A. (1936). The ego and the mechanisms of defence. International Universities Press.

Freud, S. (1894). The neuro-psychoses of defence (Vol. 3). Hogarth Press.

Godwin, M., \& Trischler, E. (2021). Reimagining the medieval: The utility of ethnonational symbols for reactionary transnational social movements. Politics and Governance, 9(3), 215-226.

Golec de Zavala, A., Cichocka, A., Eidelson, R., \& Jayawickreme, N. (2009). Collective narcissism and its social consequences. Journal of Personality and Social Psychology, 97, 1074-1096.

Griffin, R. (2012). Terrorist's creed: Fanatical violence and the human need for meaning. Palgrave Macmillan.

Gronfeldt, B., Cichocka, A., Cislak, A., Sternisko, A., \& Eker, I. (2021, July 12). A small price to pay: National narcissism predicts readiness to sacrifice in-group members to defend the in-group's image [Paper presentation]. International Society for Political Psychology 2021 Conference, Montreal, Canada.

Halperin, E. (2008). Group-based hatred in intractable conflict in Israel. Journal of Conflict Resolution, 52(5), 713-736.

Hoggett, P. (2018). Ressentiment and grievance. British Journal of Psychotherapy, 34(3), 393-407.

Hoggett, P., Wilkinson, H., \& Beedell, P. (2013). Fairness and the politics of resentment. Journal of Social Policy, 42(3), 567-585.

Katsafanas, P. (in press). Group fanaticism and narratives of ressentiment. In L. Townsend, H. B. Schmid, M. Staudigl, \& R. R. Tietjen (Eds.), The philosophy of fanaticism: Epistemic, affective, and political dimensions. Routledge.

Kaya, A. (2021). Islamist and Nativist reactionary radicalization in Europe. Politics and Governance, 9(3), 204-214.

Kazlauskaite, R., \& Salmela, M. (2021). Mediated emotions: Shame and pride in Polish right-wing media coverage of the 2019 European Parliament elections. Innovation: The European Journal of Social Science Research. Advance online publication. https://doi. org/10.1080/13511610.2021.1952551

Kenny, A. (1963). Action, emotion and will. Routledge.

Kernberg, O. (1976). Object-relations: Theory and clinical psychoanalysis. Jason Aronson.

Kiss, B. (2021). Double ressentiment: The political communication of Kulturkampf in Hungary. Politics and Governance, 9(3), 227-236.

Klein, M. (1958). On the development of mental functioning. The International Journal of Psychoanalysis, 39, 84-90.

Klein, M. (1959). Our adult world and its roots in infancy. In M. Klein (Ed.), Envy and gratitude and other works 1946-1963 (pp. 247-263). Free Press. http://dx.doi. org/10.1177/001872675901200401

Kohut, H. (1984). How does analysis cure? University of 
Chicago Press.

Laing, R. D. (1961). The self and others. Tavistock Publications.

Langman, L., \& Morris, D. (2003). Islamic terrorism: From retrenchment to ressentiment and beyond. In $\mathrm{H}$. Kushner (Ed.), Essential readings on political terrorism: Analyses of problems and prospects for the 21st century. Gordian Knot Books.

Latif, M., Blee, K., DeMichele, M., \& Simi, P. (2018). How emotional dynamics maintain and destroy white supremacist groups. Humanity \& Society, 42(4), 480-501.

Lazarus, R. S. (1991). Emotion and adaptation. Oxford University Press.

Lewis, H. (1971). Shame and guilt in neurosis. International Universities Press.

Lewis, M. (1995). Shame: The exposed self. Free Press.

Mayer, S. J., \& Nguyen, C. G. (2021). Angry reactionary narcissists? Anger activates the link between narcissism and right-populist party support. Politics and Governance, 9(3), 248-259.

Meltzler, B. N., \& Musolf, G. R. (2002). Resentment and ressentiment. Sociological Inquiry, 72(2), 240-255.

Mishra, P. (2017). The age of anger. Farrar, Straus, and Giroux.

Nietzsche, F. (1961). Genealogy of morals. Cambridge University Press. (Original work published 1885)

Poellner, P. (2011). Ressentiment and morality. In S. May (Ed.), A critical guide to Nietzsche's Genealogy of Morality (pp. 120-141). Routledge.

Posłuszna, E., \& Posłuszny, J. (2015). The trouble with ressentiment. Ruch Filozoficzny, 71(4), 87-104. http://dx.doi.org/10.12775/RF.2015.006

Rodax, N., Wrbouschek, M., Hametner, K., Paloni, S., Ruck, N., \& Brixel, L. (2021). Ressentiment as morally disclosive posture? Conceptual issues from a psychological point of view. Review of Philosophy and Psychology. Advance online publication. https://doi.org/ 10.1007/s13164-021-00546-5

Salice, A. (2020). I hate you. On hatred and its paradigmatic forms. Phenomenology and the Cognitive Sciences. Advance online publication. https://doi.org/ 10.1007/s11097-020-09668-0

Salmela, M. (2019). Shame and its political consequences in the age of neoliberalism. In C. Mun (Ed.), Interdisciplinary perspectives on shame: Methods, theories, norms, cultures, and politics (pp. 177-198). Lexington Books.

Salmela, M., \& Salice, A. (2020). What are emotional mechanisms? [Paper presentation]. University of
Birmingham Political Psychology Seminar, UK.

Salmela, M., \& von Scheve, C. (2017). Emotional roots of right-wing political populism. Social Science Information, 56(4), 567-595.

Sandel, M. (2020). The tyranny of merit. Farrar, Straus \& Giroux.

Scheff, T. J. (1994). Bloody revenge. Emotions, nationalism, and war. Authors Guild.

Scheler, M. (1961). Ressentiment. Marquette University Press. (Original work published 1915)

Smith, E. R., Seger, C. R., \& Mackie, D. M. (2007). Can emotions be truly group level? Evidence regarding four conceptual criteria. Journal of Personality and Social Psychology, 93(3), 431-46.

Sullivan, G. B. (2021). Political reactionism as affective practice: UKIP supporters and non-voters in pre-Brexit England. Politics and Governance, 9(3), 260-273.

Sullivan, G. B., \& Day, C. R. (2019). Collective emotions in celebratory, competitive, and conflictual contexts: Exploring the dynamic relations between group-based and collective pride and shame. Emotions: History, Culture, Society, 3, 202-222.

Szanto, T. (2019). In hate we trust: The collectivization and habitualization of hatred. Phenomenology and the Cognitive Sciences. Advance online publication. https://doi.org/10.1007/s11097-018-9604-9

Szanto, T. (in press). Sacralizing hostility: Fanaticism as a group-based affective mechanism. In M. Staudigl, $\mathrm{H}$. B. Schmid, L. Townsend, \& R. R. Tietjen (Eds.), Confronting fanaticism. Theoretical and applied perspectives. Routledge.

TenHouten, W. (2018). From ressentiment to resentment as a tertiary emotion. Review of European Studies, 10(4). https://doi.org/10.5539/res.v10n4pxx

Turner, J. (2007). Self, emotions, and extreme violence: Extending symbolic interactionist theorizing. Symbolic Interaction, 30, 501-530.

Ure, M. (2014). Resentment/ressentiment. Constellations, 22(4), 599-613.

Vaillant, G. E. (1993). The wisdom of the ego. Harvard University Press.

Vaillant, G. E. (1994). Ego mechanisms of defense and personality psychopathology. Journal of Abnormal Psychology, 103, 44-50.

Walker, R. (2014). The shame of poverty. Oxford University Press.

Winnicott, D. W. (1965). The maturational processes and the facilitating environment. The Hogarth Press.

Winnicott, D. W. (1971). Playing and reality. Tavistock.

\section{About the Authors}

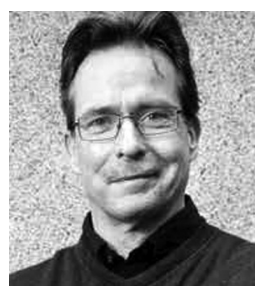

Mikko Salmela is an Adjunct Professor of Practical Philosophy and a Member of the Helsinki Hub on Emotions, Populism, and Polarisation (HEPP) at the University of Helsinki. He is also Associate Professor at the Centre for Subjectivity Research, University of Copenhagen. His main research interests are in empirically informed philosophy of emotion, philosophical and political psychology, and philosophy of sociality. 


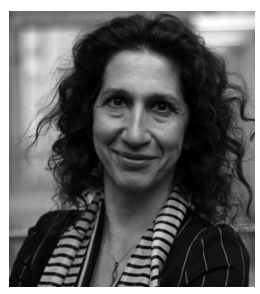

Tereza Capelos is Associate Professor in Political Psychology and Director of the Institute for Conflict Cooperation and Security (ICCS) at the University of Birmingham. She is the President of the International Society of Political Psychology, Standing Group Co-Convener for the ECPR Political Psychology Standing Group and Co-Editor of the Palgrave Series in Political Psychology. Her research examines reactionary orientations and ressentimentful affect as psychological expressions of grievance politics, and the role of uncertainty and affective ambivalence in establishing trust during international crises and tensions. 